\title{
EDUCAÇÃO PARA O DESENVOLVIMENTO SUSTENTÁVEL: UM ESTUDO DE CASO NOS CURSOS DE SECRETARIADO EXECUTIVO
}

\section{EDUCATION FOR SUSTAINABLE DEVELOPMENT: A CASE STUDY IN THE SECRETARIAT UNDERGRADUATE PROGRAMS}

\section{Luciana Nunes de Oliveira}

Mestre em Administração pela Universidade Federal do Rio Grande do Sul - UFRGS Secretária Executiva da Universidade Federal de Santa Maria - UFSM

E-mail: nunesoliveira.luciana@ hotmail.com (Brasil)

\section{Pablo Pedrosa Teixeira de Oliveira}

Especialização em Gestão da Produção também pela Universidade Federal de Viçosa - UFV Secretário Executivo da Universidade Federal de Itajubá - UNIFEI E-mail: pablo.oliveira@yahoo.com.br (Brasil)

\section{Nanci Fernandes de Paula}

Graduação em secretariado executivo trilíngue pela Universidade Federal de Viçosa - UFV Secretária Executiva da Fundação Arthur Bernardes - FUNARBE

E-mail: nancipaula@gmail.com (Brasil) 


\title{
EDUCAÇÃO PARA O DESENVOLVIMENTO SUSTENTÁVEL: UM ESTUDO DE CASO NOS CURSOS DE SECRETARIADO EXECUTIVO
}

\section{RESUMO}

O conceito de desenvolvimento sustentável tem sido usado em diferentes contextos desde sua divulgação em 1987 pelo Relatório Brundtland (também conhecido como Relatório "Nosso Futuro Comum") da Comissão Mundial para o Meio Ambiente e Desenvolvimento (CMMAD). Tendo em vista que a educação constitui um dos principais motores da construção de um futuro sustentável, as Instituições de Ensino Superior (IES) precisam preparar os futuros profissionais para que os mesmos possam atender a demanda do mercado. E isso significa que disciplinas voltadas para o desenvolvimento sustentável (DS) precisam estar inseridas nas matrizes curriculares dos cursos. Com isso, o objetivo deste estudo é verificar se os cursos de graduação em Secretariado Executivo possuem disciplinas que capacitam a formação de profissionais comprometidos com o DS. Foi realizada uma pesquisa descritiva que contou com a amostra de 86 cursos de Secretariado Executivo no grau bacharelado e modalidade presencial. Concluiu-se que apenas 26 cursos, de 23 IES, possuem disciplinas relacionadas à educação para o desenvolvimento sustentável. Este número mostra que os cursos estudados ainda não possuem dentre seus objetivos formar profissionais preparados para a realidade atual. Pode-se inferir também que para que o estudante atinja o perfil do profissional de Secretariado Executivo, constante nas diretrizes curriculares citadas na Resolução n. 3 de 2005, a educação voltada para o desenvolvimento sustentável deve fazer parte da estrutura curricular - o que permitirá que ele tenha postura crítica e reflexiva sobre todos os aspectos da tomada de decisão do gestor que está assessorando.

Palavras chave: Educação para o Desenvolvimento Sustentável; Educação Ambiental; Secretariado Executivo.

\section{EDUCATION FOR SUSTAINABLE DEVELOPMENT: A CASE STUDY IN THE SECRETARIAT UNDERGRADUATE PROGRAMS}

\begin{abstract}
The concept of sustainable development has been used in different contexts since its release in 1987 by the Brundtland Report (also known as Report "Our Common Future") of the World Commission on Environment and Development (WCED). Given that education is a major driver for building a sustainable future, the Higher Education Institutions (HEIs) need to prepare future professionals so they can meet the market demand. This means that subjects focused on sustainable development (SD) must be inserted on the curriculum of the courses. Thus, the aim of this study is to verify if the Secretarial Science undergraduate programs offer subjects that enable the formation of professionals committed to the SD. We conducted a descriptive study that included the sample of 86 bachelor's degree programs in Secretarial Science programs (classroom courses). We concluded that only 26 undergraduate programs, of 23 HEIs, have subjects related to education for sustainable development. This figure shows that the courses analyzed still lack among its aims the training of professionals prepared to the present reality. We can also infer that for the student to reach the professional profile of the Executive Secretary, stated in the curriculum guidelines cited in Resolution no. 3/2005, education focused on sustainable development should be part of the curriculum structure, allowing the professional to have a critical and reflective posture about all aspects of decision-making of the manager he or she is assisting.
\end{abstract}

Keywords: Education for Sustainable Development; Environmental Education; Secretarial Science Undergraduate Program.

Revista de Gestão e Secretariado - GeSec, São Paulo, v. 5, n. 1, p 82-103, jan./abr. 2014. 


\section{INTRODUÇÃO}

O conceito de desenvolvimento sustentável tem sido usado em diferentes contextos desde sua divulgação em 1987 pelo Relatório Brundtland (também conhecido como Relatório "Nosso Futuro Comum") da Comissão Mundial para o Meio Ambiente e Desenvolvimento (CMMAD).

Dessa forma, os gestores viram-se pressionados a introduzir o tema em suas empresas e na maneira como estavam administrando seus negócios. Muitas empresas passaram a adotar como missão, visão e metas um plano de trabalho voltado para ações sustentáveis, na tentativa de gerir seus processos de forma mais limpa e ecologicamente correta, uma vez que não apenas os gestores precisavam ter conhecimento do tema, mas toda a equipe.

Tendo em vista que a educação constitui um dos principais motores da construção de um futuro sustentável, as Instituições de Ensino Superior (IES) precisam preparar os futuros profissionais para que estes possam atender a demanda do mercado. E isso significa que disciplinas voltadas para o desenvolvimento sustentável precisam estar inseridas nas matrizes curriculares dos cursos.

Com a presença constante nas discussões, em diversos aspectos, e em grande número de estudos acerca do desenvolvimento sustentável por parte das organizações, disciplinas que envolvem a questão socioambiental estão cada vez mais presentes nos currículos de vários cursos de graduação e formação profissional, principalmente naqueles com características multidisciplinares, como os cursos nas áreas de ciências humanas e sociais aplicadas.

É neste momento que o profissional de secretariado executivo passa a ser questionado sobre suas capacidades de trabalhar com ações sustentáveis, já que o mercado começara a exigir que os profissionais tenham este perfil e essa consciência sobre as ações junto à sociedade de uma forma geral. Com isso, a questão que o presente estudo pretende responder é: os cursos de graduação em Secretariado Executivo possuem disciplinas que capacitam a formação de profissionais comprometidos com o desenvolvimento sustentável?

Com a análise feita na pesquisa, busca-se demonstrar se esses cursos proporcionam aos seus estudantes disciplinas que forneçam o conhecimento e o preparo necessário para lidar com questões que possam vir a surgir no desempenho das atividades do profissional de secretariado frente aos desafios propostos pela dinâmica organização X sociedade.

Com a finalidade de responder a questão apresentada, o estudo está dividido em três partes, além das considerações finais. Inicialmente é feita uma revisão de literatura. Logo após o método é apresentado. Em seguida, a análise e discussão dos dados são realizadas.

Revista de Gestão e Secretariado - GeSec, São Paulo, v. 5, n. 1, p 82-103, jan./abr. 2014. 


\section{REVISÃO DE LITERATURA}

De acordo com Kraemer (2004), o modelo de crescimento econômico gerou enormes desequilíbrios, fazendo com que se consolidasse a percepção de que é imperativo o desenvolvimento, mas sempre em harmonia com as limitações ecológicas do planeta. Ou seja, sem dizimar o ambiente, para que as gerações futuras tenham chance de existir e viver bem, de acordo com as suas necessidades (melhoria da qualidade de vida e das condições de sobrevivência).

Diante disso, o debate da gestão social e das questões ambientais vem ganhando crescente importância no contexto organizacional, público ou empresarial, em razão dos constantes alertas de cientistas e de organismos multilaterais sobre as consequências da má gestão ambiental, além da percepção dos gestores de que o tema será importante para a decisão dos consumidores (Mazza, Oliveira, Ramos \& Costa, 2011).

Com isso, neste artigo será revisada a literatura concernente ao desenvolvimento sustentável, educação ambiental e educação para o desenvolvimento sustentável, além do papel das instituições de ensino superior com o desenvolvimento sustentável (DS).

\subsection{DESENVOLVIMENTO SUSTENTÁVEL}

O Relatório Brundtland (também conhecido como Relatório "Nosso Futuro Comum") lançado em 1987 pela Comissão Mundial para o Meio Ambiente e Desenvolvimento (CMMAD), veio atentar para a necessidade de um tipo de desenvolvimento capaz de beneficiar todo o planeta. Este Relatório difundiu a ideia de que o desenvolvimento sustentável "é aquele desenvolvimento que satisfaz as necessidades do presente sem colocar em risco a satisfação das necessidades das futuras gerações" (World Commission Environment Development, 1987).

De acordo com Sneddon, Howarth e Norgaard (2006), o Relatório Brundtland é o ponto de partida mais amplamente aceito pelos estudiosos e profissionais envolvidos com o meio ambiente e os dilemas do desenvolvimento. Os mesmos autores afirmam que o Relatório estabeleceu o desenvolvimento sustentável como um componente do desenvolvimento dos pensamentos e das práticas internacionais. Ele também ajudou a desencadear o que muitos discutem hoje, que são os objetivos do desenvolvimento sustentável: a melhoria do bem-estar humano, a distribuição mais equitativa dos benefícios de utilização dos recursos através e dentro das sociedades e o desenvolvimento que garanta a integridade ecológica.

Revista de Gestão e Secretariado - GeSec, São Paulo, v. 5, n. 1, p 82-103, jan./abr. 2014. 
Entretanto, Lélé (1991, p. 61 citado por Barbieri \& Silva, 2011) advertia sobre o uso indiscriminado da expressão desenvolvimento sustentável em uma época em que ainda não havia se tornado popular, como hoje se observa (p. 18). As diversas interpretações desta expressão estão representadas na Figura 1.

Figura 1 - Desenvolvimento sustentável: conceitos, significados e interpretações

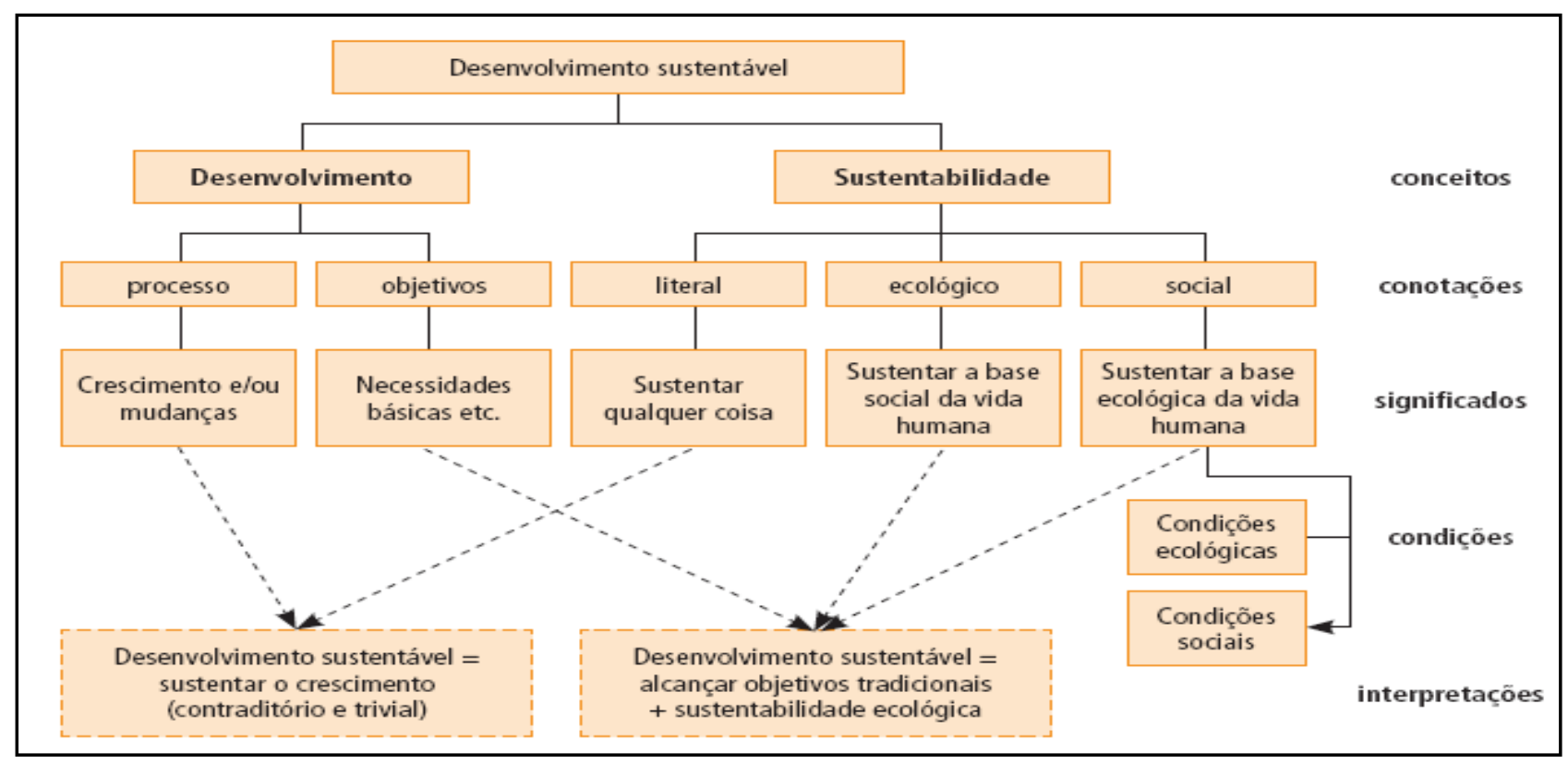

Fonte: Lélé (1991, p. 608) citado por Barbieri \& Silva (2011, p. 19).

Ainda seguindo as ideias de Lélé (1991, p. 61 citado por Barbieri \& Silva, 2011), desenvolvimento sustentável é um metaobjetivo que une todo o mundo, do industrialista, com sua mente voltada para o lucro, ao agricultor de subsistência, que minimiza os riscos de sua atividade, ao trabalhador e aos programas sociais ligados à busca de equidade com o indivíduo do primeiro mundo, preocupado com a poluição ou com a vida selvagem, bem como o formulador de políticas públicas maximizadoras do crescimento, o burocrata orientado por objetivos e, por conseguinte, o político interessado em votos (p. 18).

Para Almeida e Kautzmann (2012), os modelos de desenvolvimento propostos pelos países desenvolvidos legaram-nos uma situação socioambiental insustentável, conforme as conclusões da Rio-92. Esse encontro que teve como ponto central introduzir como um modelo de crescimento econômico o desenvolvimento sustentável, proporcionando assim a redução do consumo e visando atingir um equilíbrio ecológico. Segundo os autores, para reverter tal situação, a promoção da sustentabilidade "salta da utopia para assumir o papel de estratégia para sobrevivência da espécie

Revista de Gestão e Secretariado - GeSec, São Paulo, v. 5, n. 1, p 82-103, jan./abr. 2014. 
humana, buscando na Educação Ambiental (EA) um importante instrumento de materialização na busca de um novo paradigma, de um novo estilo de vida" (Almeida \& Kautzmann, 2012, p. 2).

Diante do exposto, conclui-se que a crise ambiental requer também soluções educacionais que se caracterizem em mudanças de hábitos, de valores e de atitudes. Debates sobre o meio ambiente e a sustentabilidade nos direcionam a formar profissionais que compreendam e, principalmente, tenham atitudes proativas nessa discussão (Almeida \& Kautzmann, 2012).

Com isso, para Tauchen e Brandli (2006), o papel de destaque assumido pelas IES no processo de "desenvolvimento tecnológico, na preparação de estudantes e fornecimento de informações e conhecimento, pode e deve ser utilizado também para construir o desenvolvimento de uma sociedade sustentável e justa" (p. 1).

\subsection{EDUCAÇÃO AMBIENTAL E EDUCAÇÃO PARA O DESENVOLVIMENTO SUSTENTÁVEL}

Para Kraemer (2004b), a educação ambiental é "parte vital e indispensável na tentativa de se chegar ao desenvolvimento sustentável, pois é a maneira mais direta e funcional de se atingir pelo menos uma de suas metas: a participação da população" (p. 6). Para Almeida e Kautzmann (2012), com relação ao aspecto ético da EA, pode-se concluir que a conduta ética passa a ser, entre os educadores, "uma questão central, em que os modelos de desenvolvimento sustentáveis contenham valores que reafirmem a indissociabilidade entre o social, o ambiental e o econômico" (p. 10).

Esta visão, de se criar uma sociedade com um pensamento voltado para as questões que envolvem a sustentabilidade e o meio ambiente, já estava presente quando, na criação da Lei n. 5.197/67, que trata sobre a proteção da fauna, incluiu no seu artigo 35 o seguinte: "§ $1^{\circ}$ - Os Programas de ensino de nível primário e médio deverão contar pelo menos com duas aulas anuais sobre a matéria a que se refere o presente artigo" (Lei 5.197, 1967). De acordo com Barbieri e Silva (2011)educação para a sustentabilidade, educação para um futuro sustentável, educação para o desenvolvimento sustentável passaram a ser expressões usadas como sinônimas nos documentos da ONU e da Unesco a partir de então. Como diz um documento da Unesco de 1997, as raízes de uma educação para o desenvolvimento sustentável estão firmemente implantadas na EA, que, em sua breve trajetória, se esforçou para alcançar metas e resultados similares aos inerentes ao conceito de desenvolvimento sustentável, e compreendem um amplo espectro de dimensões ambientais, sociais, éticas, econômicas e culturais. Esse documento dá a entender que a EDS é uma evolução da EA. (p.

Revista de Gestão e Secretariado - GeSec, São Paulo, v. 5, n. 1, p 82-103, jan./abr. 2014. 
$62)$.

No presente estudo, a teoria de que a EA é um componente da EDS e um dos que contribuíram para sua conceituação será utilizada. Enquanto a EDS se volta para as dimensões sociais, políticas e econômicas, a EA se concentra na dimensão ambiental. A Figura 2 representa opiniões dos participantes de uma pesquisa com 50 participantes de 25 países e apresentam quatro perspectivas de relação entre EA e EDS, e a maioria deles considerou a EDS como o próximo estágio na evolução da EA ou uma nova geração de EA (Barbieri \& Silva, 2011).

Figura 2 - Perspectivas sobre a relação entre EA e EDS.

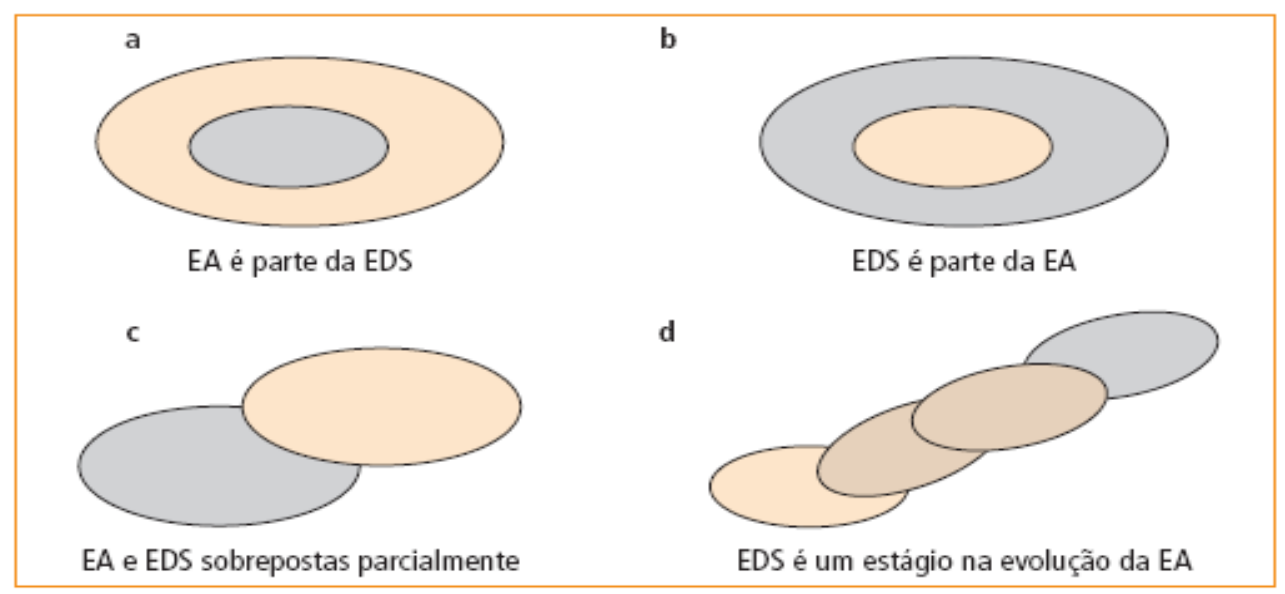

Fonte: Hasselink, Kempen e Wals (2000, p. 12) apud Barbieri, Silva (2011, p. 14)

Diante disso, para a Unesco (2005), “a educação para o desenvolvimento sustentável é um processo em que se aprende a tomar decisões que levem em consideração o futuro em longo prazo de igualdade, economia e ecologia de todas as comunidades" (p. 42). Diante disso, é importante destacar a questão educacional como uma prática fundamental para que as IES, pela formação, possam contribuir na qualificação de seus egressos, futuros tomadores de decisão, para que incluam em suas práticas profissionais a preocupação com as questões ambientais (Tauchen \& Brandli, 2006).

\subsection{O PAPEL DAS INSTITUIÇÕES DE ENSINO SUPERIOR}

Ao longo da história, muitas foram as mudanças e as conquistas em relação ao desenvolvimento da educação. Tais mudanças são vistas não como resultado de um fenômeno novo no contexto educacional, mas como consequência de novas ideias que estimulam uma transformação em toda sociedade. Dessa forma, mudanças e, consequentemente, inovações não

Revista de Gestão e Secretariado - GeSec, São Paulo, v. 5, n. 1, p 82-103, jan./abr. 2014. 
podem ser negligenciadas pelas Instituições de Ensino Superior (Fiates, Parente, Leite \& Pfitscher, 2012).

Segundo a Unesco (2000), para responder à complexidade da sociedade contemporânea, o desafio da educação superior é inovar no seu modelo pedagógico justamente em relação aos princípios éticos, à responsabilidade social e à sustentabilidade das organizações e consequentemente das nações, inserindo nos projetos pedagógicos uma visão de mundo mais global.

Para Mazza et al (2011) "cabe às instituições de ensino a tarefa de protagonizar o desenvolvimento de projetos de educação e de gestão ambiental, como um meio viável para uma formação profissional consistente" (p. 8). Entretanto, para Almeida e Kautzmann (2012), embora o tema ambiental esteja na ordem do dia em qualquer ação pública ou privada, de cunho local ou global, as questões do meio ambiente na universidade e nas empresas continuam a serem tratadas de forma departamentalizada; as propostas multidisciplinares carecem da interdisciplinaridade, e seus conceitos são abordados de forma fragmentada e isolada de um contexto sistêmico. (p. 2)

Ainda segundo os autores, uma possível estratégia para trabalhar a interdisciplinaridade, embasada na pedagogia freireana, seria, segundo Hogan (1995), ecologizar as disciplinas. Primeiro abrindo espaços nos currículos para a temática ambiental, depois criando vínculos informais com outras disciplinas, e, finalmente, como meta maior, promovendo a reformulação das disciplinas (Almeida \& Kautzmann, 2012).

Podemos observar que trabalhar as disciplinas de maneira conjunta, é assunto tratado também por meio da Lei n. 9.795/99, que orienta a inclusão da educação ambiental em todos os níveis do ensino formal e informal, sendo desenvolvida "como uma prática educativa integrada, contínua e permanente [...]" e, portanto, "não deve ser implantada como disciplina específica no currículo de ensino" (Lei n. 9.795, 1999).

De acordo com Almeida e Kautzmann (2012), universidade e empresa são partes de um mesmo sistema com a incumbência de produzir bens e conhecimento, onde uma promove o crescimento da outra. Assim, ambas são responsáveis pela formação de profissionais capacitados para a produção de bens, com qualidade e sustentabilidade ambiental. A inclusão da variável ambiental, tanto como da variável técnica, social e econômica, é imprescindível para a produção e a aplicação do conhecimento.

Entretanto, conforme o trabalho apresentado por Demajorovic e Junior (2006), observa-se que na maioria dos gestores organizacionais, existe uma falta de conhecimento e um pequeno grau 
de conscientização crítica nas questões ambientais, por não terem recebido, desde sua formação no ensino fundamental, as informações que lhes dariam no mínimo um aporte teórico para repensar seus hábitos, valores e ações.

Portanto, visto que os profissionais envolvidos com a área de gestão possuem o desafio de minimizar os impactos negativos de decisões irresponsáveis que comprometam a organização, a sociedade e o futuro das nações, em 2007, foram desenvolvidos por uma organização internacional de sessenta reitores, presidentes de universidades e representantes oficiais das principais escolas de negócios e instituições acadêmicas os Princípios para Educação Empresarial Responsável (PRME) (Princípios para Educação Empresarial Responsável [PRME], 2007).

De acordo com Fiates et al (2012) “esses princípios constituem uma plataforma voluntária de envolvimento de instituições acadêmicas, baseada em valores representados pelo tripé: Ética, Responsabilidade Social e Sustentabilidade” (p. 3):

Princípio 1 (propósito): Desenvolveremos as capacidades dos estudantes para que possam ser futuros geradores de valores sustentáveis para os negócios e a sociedade como um todo e para lutar por uma economia global inclusiva e sustentável.

Princípio 2 (valores): Incorporaremos, em nossas atividades acadêmicas e curriculares, os valores de responsabilidade social global, conforme considerado em iniciativas internacionais, como o Pacto Global das Nações Unidas.

Princípio 3 (método): Criaremos estruturas educacionais, materiais, processos e condições que permitam realizar experiências de aprendizagem eficazes para a liderança responsável.

Princípio 4 (pesquisa): Engajar-nos-emos em pesquisas conceituais e empíricas que aumentem nosso entendimento sobre o papel e os impactos das empresas na criação de valor social, ambiental e econômico sustentável.

Princípio 5 (parceria): Interagiremos com gestores de empresas para estender nosso conhecimento sobre seus desafios concernentes à junção das responsabilidades sociais e ambientais e para explorar conjuntamente abordagens eficazes para responder a esses desafios.

Princípio 6 (diálogo): Facilitaremos e apoiaremos o diálogo e o debate entre educadores, empresas, consumidores, mídia, organizações da sociedade civil e outros grupos de interesse e partes interessadas sobre questões críticas sobre responsabilidade social e sustentabilidade global. Entendemos que nossas próprias práticas organizacionais devem servir como exemplo dos valores e das atitudes que transmitimos aos nossos alunos.

De acordo com Barbieri e Silva (2011), esse tipo de iniciativa voluntária, como o PRM, "visa colocar as IES como parceiras privilegiadas do desenvolvimento sustentável de modo explícito" (p. 27), facilitando a inserção das IES no movimento do desenvolvimento sustentável e favorecendo o aprendizado entre as signatárias de um mesmo acordo.

Segundo a Unesco (2007), as IES deveriam expressar sua convicção na adoção de valores universais em seus currículos de ensino e atividades de pesquisa, contribuindo de fato com a construção de uma sociedade mais justa, pois para a Unesco (2005), “a educação é o principal agente de transformação para o desenvolvimento sustentável, aumentando a capacidade das pessoas de transformarem sua visão de sociedade em realidade" (p.41).

Revista de Gestão e Secretariado - GeSec, São Paulo, v. 5, n. 1, p 82-103, jan./abr. 2014. 


\section{MÉTODO}

De acordo com os objetivos propostos, trata-se de uma pesquisa descritiva, uma vez que como defendido por Gil (2002), o objetivo desse tipo de pesquisa é descrever as características de determinada população ou fenômeno e também demonstrar o estabelecimento de relações entre variáveis, além de se preocupar em identificar os fatores que determinam ou que contribuem para a ocorrência de determinados fenômenos.

Como população do estudo, têm-se as Instituições de Ensino Superior cadastradas no site eMEC que ofertam o curso de Secretariado Executivo no grau bacharelado e na modalidade presencial. Foram desconsiderados os cursos de grau tecnológico e sequencial. A amostra escolhida para o presente estudo foram os cursos oferecidos no ano de 2012. As instituições que possuíam autorização para ofertar o curso, mas não estavam ofertando, foram desconsideradas. Também foram desconsideradas as IES que não possuíam as matrizes curriculares em seus websites ou então as IES que não responderam aos e-mails dos pesquisadores que as solicitaram.

Com isso, inicialmente foi feita uma busca no site do MEC (e-MEC) com a palavra-chave secretariado executivo. Logo em seguida foi realizado um filtro para o grau bacharelado e modalidade presencial. Foram identificados 105 cursos. Desconsiderando os casos supracitados, a amostra deste estudo contou com 86 cursos de Secretariado Executivo. Por fim, a estrutura curricular desses cursos foi pesquisada no website de cada instituição com o objetivo de verificar se os cursos estudados oferecem disciplinas que capacitam a formação de profissionais comprometidos com o desenvolvimento sustentável. Usaram-se as seguintes palavras-chaves: sustentabilidade, responsabilidade social, gestão ambiental, meio ambiente, educação ambiental e desenvolvimento sustentável. Foram identificados 27 cursos.

Como limitação do estudo, tem-se a existência das disciplinas de tópicos especiais, atividades complementares e seminários que mudam de ementa conforme a necessidade do curso, e pode ser que estudem temas relacionados ao desenvolvimento sustentável. Além desta limitação, tem-se a indisponibilidade de matrizes curriculares nos websites de algumas IES e a falta de um endereço eletrônico para contato com as coordenações dos cursos, o que diminuiu a amostra do estudo.

Revista de Gestão e Secretariado - GeSec, São Paulo, v. 5, n. 1, p 82-103, jan./abr. 2014. 


\section{ANÁLISE E DISCUSSÃO DOS DADOS}

\subsection{O CURSO DE SECRETARIADO EXECUTIVO}

O curso de Secretariado Executivo tem como característica a pluralidade dos temas abordados na formação dos profissionais. Nesse leque de disciplinas oferecidas, grande parte está voltada para a administração, seja na administração propriamente dita, ou em outras áreas como o direito administrativo, ética e redação empresarial, entre outras.

O enfoque administrativo dado ao curso está justificado pelo que diz o parágrafo único do artigo terceiro das Diretrizes Curriculares do Curso de Secretariado Executivo, que cita a importância do conhecimento da organização e de suas ações como um todo para o profissional exercer com excelência suas atribuições:

o bacharel em Secretariado Executivo deve apresentar sólida formação geral e humanística, com capacidade de análise, interpretação e articulação de conceitos e realidades inerentes à administração pública e privada, ser apto para o domínio em outros ramos do saber, desenvolvendo postura reflexiva e crítica que fomente a capacidade de gerir e administrar processos e pessoas, com observância dos níveis graduais de tomada de decisão, bem como capaz para atuar nos níveis de comportamento micro-organizacional, meso-organizacional e macro-organizacional (Resolução n. 3, 2005).

Com isso, os cursos de secretariado, assim como outros cursos, têm o desafio de colaborar para uma sociedade baseada em comportamentos social e ambientalmente responsáveis e a melhoria das habilidades, valores e competências humanas para uma real participação nos processos decisórios daqueles que batem à sua porta em busca de novos conhecimentos (Salgado \& Cantarino, 2006).

\subsection{ANÁLISE E DISCUSSÃO DOS DADOS}

Após a obtenção das matrizes curriculares das amostras estudadas, foi realizada uma análise delas. A Figura 3 representa a distribuição geográfica dos 86 cursos estudados. Percebe-se maior concentração dos cursos na região Sudeste, com 32 cursos, seguido pela região Sul, Centro-Oeste, Nordeste e a menor concentração na região Norte, com apenas quatro cursos.

Revista de Gestão e Secretariado - GeSec, São Paulo, v. 5, n. 1, p 82-103, jan./abr. 2014. 
Figura 3 - Distribuição geográfica dos cursos estudados.

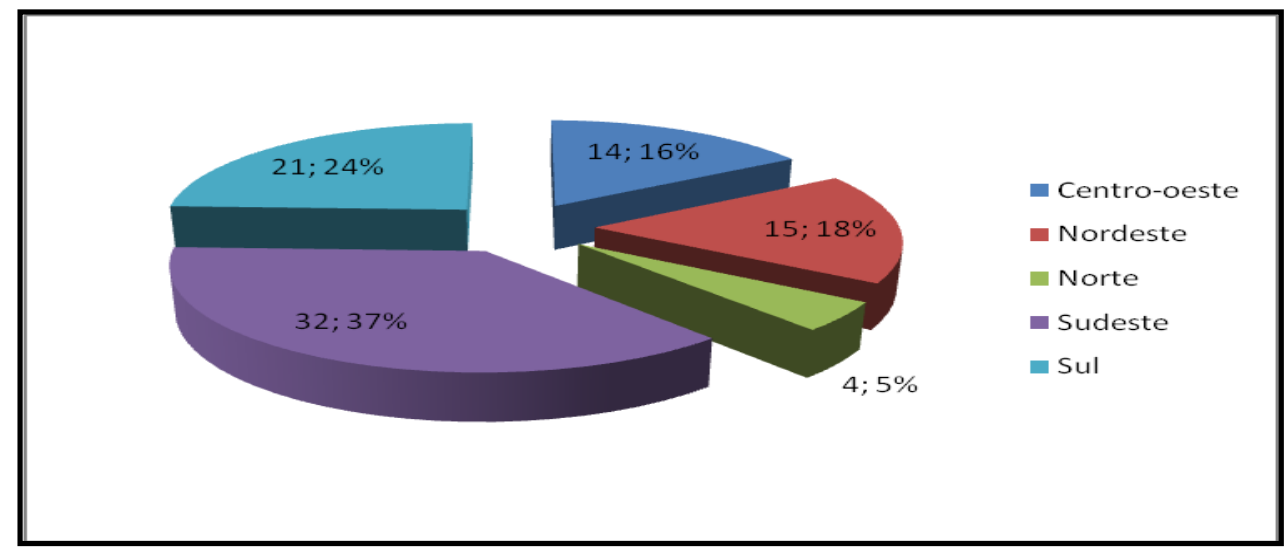

Fonte: Elaborado pelos autores.

Dos 86 cursos estudados, apenas 26 (de 23 IES) possuem disciplinas relacionadas à EDS, conforme demonstrado na Figura 4. Este percentual representa $31 \%$ da amostra estudada, o que pode ser considerado um valor baixo, tendo em vista a importância do tema para a formação profissional, conforme as ideias de Mazza et al (2011), ao citar que "cabe às instituições de ensino a tarefa de protagonizar o desenvolvimento de projetos de educação e de gestão ambiental, como um meio viável para uma formação profissional consistente" (p. 8).

Figura 4 - Cursos que possuem disciplinas relacionadas a educação para o desenvolvimento sustentável.

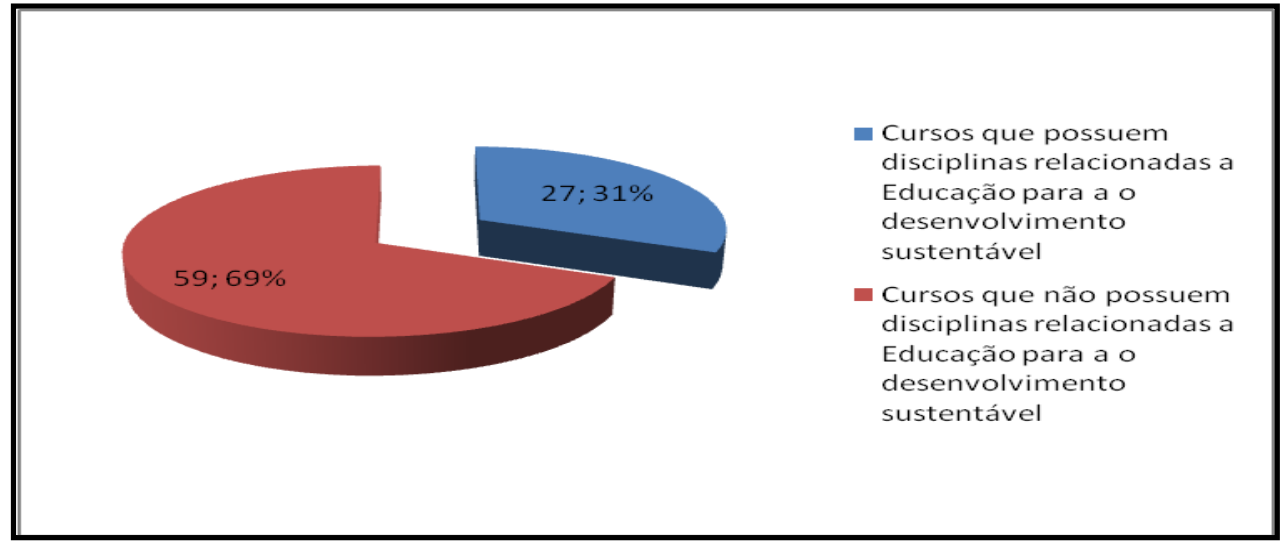

Fonte: Elaborado pelos autores.

Além disso, é de suma importância que coordenadores e professores percebam a importância dessas disciplinas nas estruturas curriculares de seus cursos, pois, de acordo com Almeida e Kautzmann (2012) debates relacionados à área do desenvolvimento sustentável levam à formação

Revista de Gestão e Secretariado - GeSec, São Paulo, v. 5, n. 1, p 82-103, jan./abr. 2014. 
de profissionais que compreendam e tenham atitudes proativas nesta questão.

Deve-se lembrar de que as disciplinas tópicos especiais, seminários e atividades complementares têm ementas flexíveis de forma a atender as demandas dos alunos e, portanto, o número de cursos com disciplinas relacionadas à EDS pode variar.

Para os 59 cursos estudados que ainda não possuem em suas matrizes curriculares disciplinas relacionadas à EDS, é importante, conforme as ideias de Almeida e Kautzmann (2012) abrir espaços nos currículos para a temática ambiental, depois criar vínculos informais com outras disciplinas, e, finalmente, como meta maior, promover a reformulação das disciplinas.

Os 26 cursos que possuem disciplinas relacionadas à Educação para o desenvolvimento sustentável são de 23 IES. A Tabela 1 representa estas instituições, a localização delas por região e a (s) disciplinas (s) ofertadas aos estudantes. Nota-se que são 24 disciplinas ofertadas, pois o Centro Universitário Assunção oferta duas disciplinas.

Tabela 1 - disciplinas relacionadas à Educação para o Desenvolvimento Sustentável.

\begin{tabular}{|c|c|c|}
\hline INSTITUIÇÃO & REGIÃO & DISCIPLINA \\
\hline Centro Universitário Assunção & Sudeste & $\begin{array}{l}\text { Gestão Secretarial, Empreendedorismo e Sustentabilidade I } \\
\text { Gestão Secretarial, Empreendedorismo e Sustentabilidade II }\end{array}$ \\
\hline Centro Universitário de Lins & Sudeste & Ética e Responsabilidade Social \\
\hline $\begin{array}{l}\text { Centro Universitário } \\
\text { Internacional }\end{array}$ & Sul & Gestão Secretarial: Empreendedorismo e Sustentabilidade \\
\hline $\begin{array}{l}\text { Escola Superior de Relações } \\
\text { Públicas }\end{array}$ & Nordeste & Responsabilidade Social \\
\hline Faculdade Afirmativo & Centro-oeste & Ética e Responsabilidade Social \\
\hline Faculdade Atenas Maranhense & Nordeste & Gestão de Meio Ambiente \\
\hline $\begin{array}{l}\text { Faculdade de Ciências Aplicadas } \\
\text { e Sociais de Petrolina }\end{array}$ & Nordeste & Desenvolvimento Sustentável \\
\hline $\begin{array}{c}\text { Faculdade de Ciências Sociais } \\
\text { Aplicadas e Humanas de } \\
\text { Garanhuns }\end{array}$ & Nordeste & Gestão Ambiental \\
\hline Faculdade Estácio de Alagoas & Nordeste & Ética e Responsabilidade Social \\
\hline Faculdade Metodista de Ciências & Sudeste & Ética Profissional e Responsabilidade Social \\
\hline
\end{tabular}

Revista de Gestão e Secretariado - GeSec, São Paulo, v. 5, n. 1, p 82-103, jan./abr. 2014. 


\begin{tabular}{|c|c|c|}
\hline Humanas e Exatas & & \\
\hline Faculdade Sant'ana & Sul & Desenvolvimento Sustentável \\
\hline Faculdade Sumaré & Sudeste & Sustentabilidade e Responsabilidade Social \\
\hline Faculdades Integradas da Upis & Sudeste & Relações Públicas e Responsabilidade Social \\
\hline Focca - Faculdade de Olinda & Nordeste & Ética e Responsabilidade Social \\
\hline $\begin{array}{c}\text { Instituto Federal de Educação, } \\
\text { Ciência e Tecnologia de Mato } \\
\text { Grosso }\end{array}$ & Centro-oeste & Gestão Ambiental \\
\hline $\begin{array}{l}\text { Pontifícia Universidade Católica } \\
\text { de São Paulo }\end{array}$ & Sudeste & Empresas e Responsabilidade Social \\
\hline $\begin{array}{c}\text { Universidade Católica do } \\
\text { Salvador }\end{array}$ & Nordeste & Educação Ambiental \\
\hline Universidade Estácio de Sá & Sudeste & Ética e Responsabilidade Social \\
\hline $\begin{array}{l}\text { Universidade Estadual de } \\
\text { Londrina }\end{array}$ & Sul & $\begin{array}{c}\text { Ética Empresarial e Responsabilidade Social para } \\
\text { Secretariado Executivo }\end{array}$ \\
\hline $\begin{array}{l}\text { Universidade Estadual do Centro } \\
\text { Oeste }\end{array}$ & Sul & $\begin{array}{c}\text { Fundamentos de Responsabilidade Social e Profissional em } \\
\text { Secretariado Executivo }\end{array}$ \\
\hline $\begin{array}{l}\text { Universidade Federal de } \\
\text { Roraima }\end{array}$ & Norte & Gestão Ambiental e Responsabilidade Social \\
\hline $\begin{array}{l}\text { Universidade Metodista de São } \\
\text { Paulo }\end{array}$ & Sudeste & Sustentabilidade \\
\hline $\begin{array}{c}\text { Universidade Regional Integrada } \\
\text { do Alto Uruguai e das Missões }\end{array}$ & Sul & Ética Empresarial e Responsabilidade Social \\
\hline
\end{tabular}

Fonte: Elaborado pelos autores.

A Tabela 1 representa a diversidade na nomenclatura das disciplinas e na maioria dos casos 
os temas são estudados concomitantemente, como por exemplo, ética e responsabilidade social, conforme Figura 5. Apenas na Faculdade de Ciências Aplicadas e Sociais de Petrolina e na Faculdade Sant'ana a disciplina recebe o nome de "Desenvolvimento Sustentável". Na Universidade Metodista de São Paulo a disciplina voltada para a área de EDS tem o nome de "Sustentabilidade".

Figura 5 - Disciplinas relacionadas à Educação para o Desenvolvimento Sustentável.

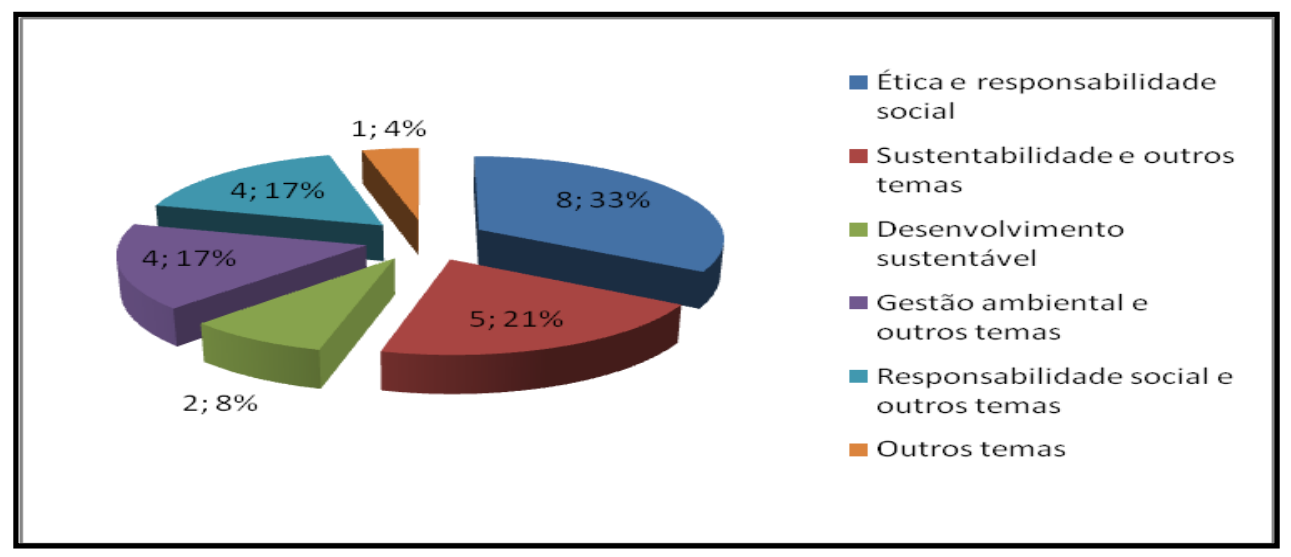

Fonte: Elaborado pelos autores.

A Figura 6 apresenta os cursos que possuem disciplinas relacionadas a educação para o desenvolvimento sustentável e sua localização por região. Percebe-se que dos 32 cursos estudados da região Sudeste, apenas oito deles, ou seja, 25\%, apresentam disciplinas relacionadas à educação para o desenvolvimento sustentável. Levando em consideração os cursos e as regiões do Brasil, $31 \%$ dos cursos que ofertam disciplinas relacionadas à EDS estão localizados na região Sudeste.

Já na região Sul, este percentual é um pouco maior (28\%), sendo que dos 21 cursos estudados, seis apresentam disciplinas relacionadas a EDS e em âmbito de Brasil, estes seis cursos representam $23 \%$.

Na região Nordeste, dos 15 cursos estudados, oito deles oferecem disciplinas relacionadas a EDS, representando 53\%. Analisando por regiões do Brasil, a região Nordeste representa $31 \%$. $\mathrm{Na}$ região Norte este percentual é de $25 \%$, já que dos quatro cursos da amostra, apenas um deles apresenta disciplina voltada para a EDS, sendo que em âmbito de Brasil, este curso representa 4\%.

Já na região Centro-Oeste, dos 14 cursos que compõem a amostra deste estudo, apenas três deles possuem disciplinas relacionadas a EDS, representando $21 \%$ da região. Em âmbito de Brasil, estes três cursos representam $11 \%$.

Comparando-se o número de cursos de Secretariado Executivo analisados por região, era esperado que a região Sudeste, por oferecer o maior número de cursos (Figura 3), obtivesse o maior

Revista de Gestão e Secretariado - GeSec, São Paulo, v. 5, n. 1, p 82-103, jan./abr. 2014. 
número de cursos oferecendo disciplinas relacionadas à EDS. Entretanto, a região Nordeste, apesar da diferença em números de cursos - menos da metade comparada à região Sudeste - apresentou o mesmo número de cursos com disciplinas relacionadas à EDS.

Figura 6 - Cursos que possuem disciplinas relacionadas à Educação para o Desenvolvimento Sustentável por região geográfica.

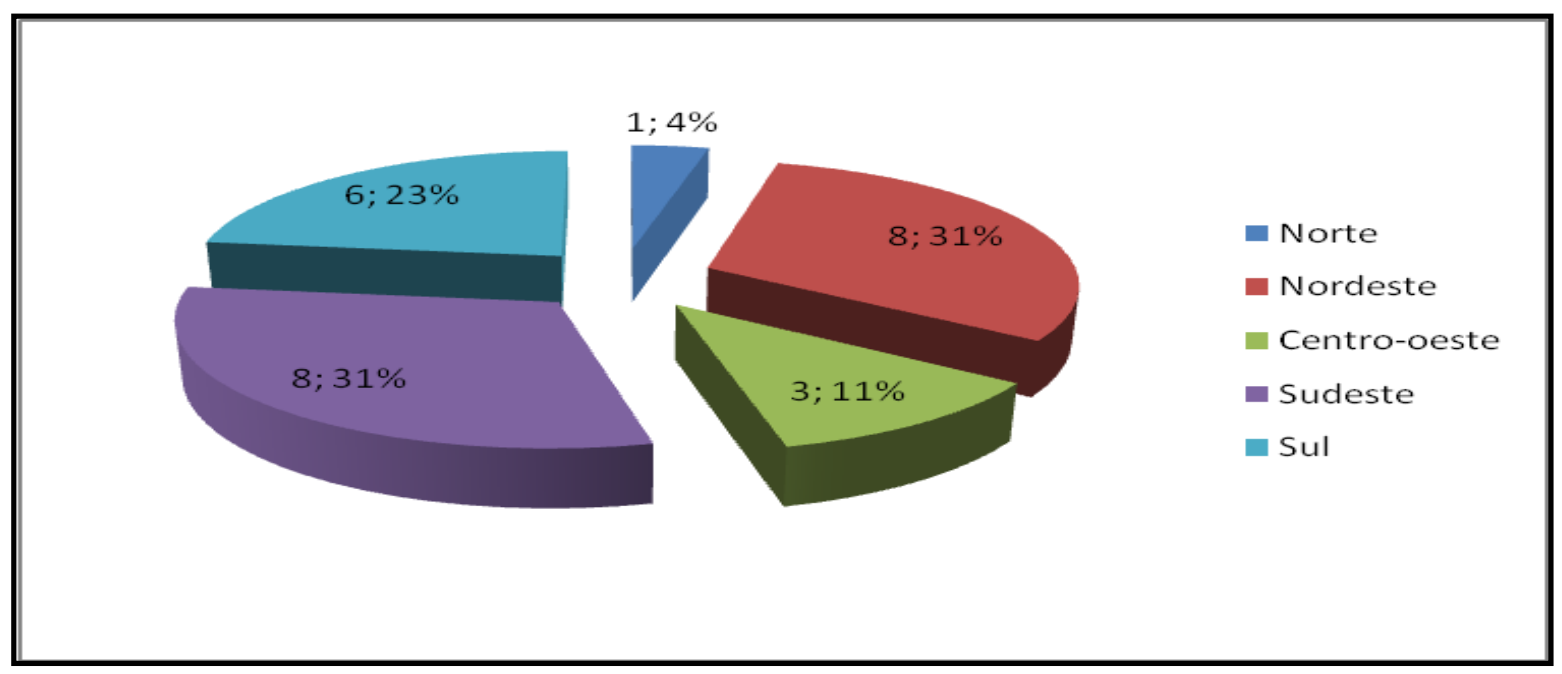

Fonte: Elaborado pelos autores.

Pode-se concluir que apesar de a região Sudeste possuir a maior quantidade de cursos de Secretariado na amostra deste estudo, a mesma não apresenta a maior porcentagem de cursos que possuem disciplinas relacionadas a EDS por região geográfica. A maior porcentagem pertence a região Nordeste, com oito cursos, em uma amostra de 15 cursos.

Com relação ao setor da educação das 23 IES que possuem cursos de Secretariado que oferecem disciplinas relacionadas a EDS, 74\% (17) delas são privadas e o restante, 26\% (seis) são IES públicas (municipais, estaduais ou federais), conforme Figura 7.

Revista de Gestão e Secretariado - GeSec, São Paulo, v. 5, n. 1, p 82-103, jan./abr. 2014. 
Figura 7 - IES que possuem disciplinas relacionadas a Educação para o Desenvolvimento Sustentável por setores da educação

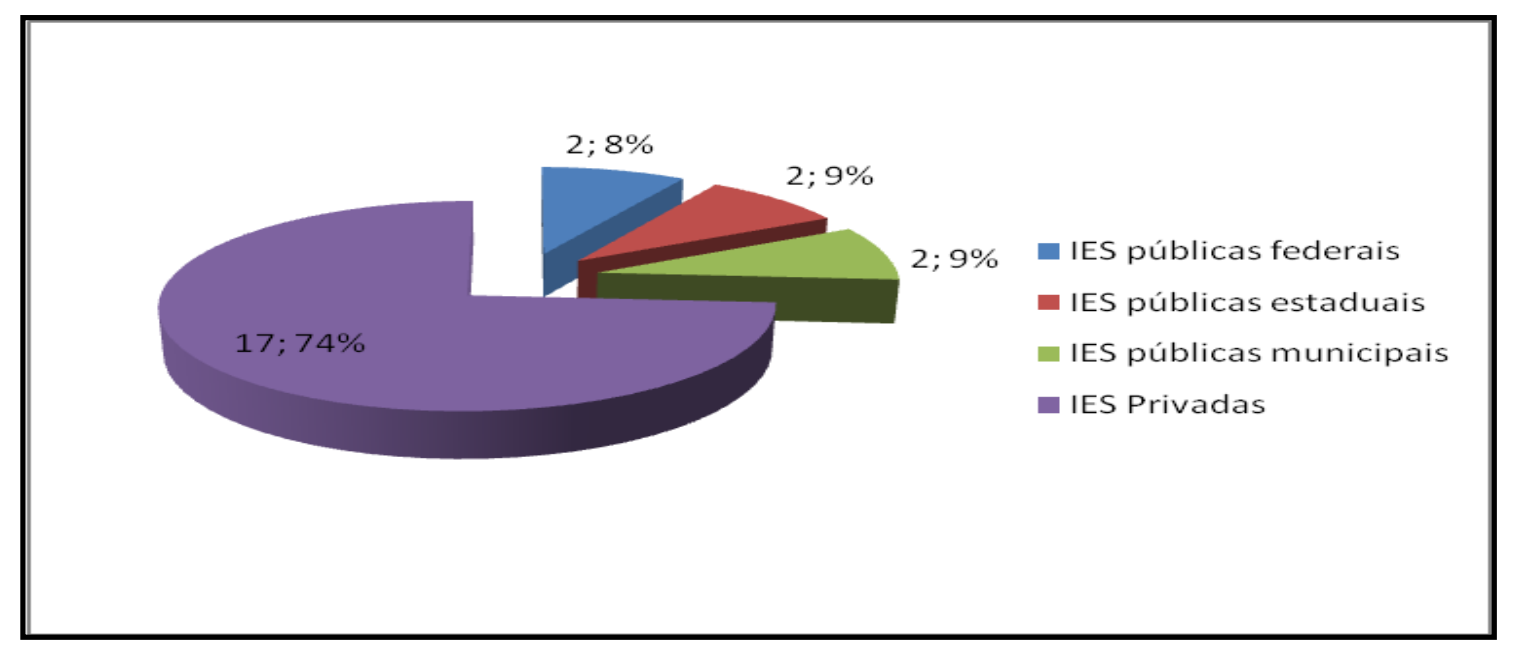

Fonte: Elaborado pelos autores.

Este dado pode ser explicado pelo fato de que as instituições privadas têm mais autonomia no que se refere à mudança de suas matrizes curriculares e ementas de disciplinas. Na universidade pública, os trâmites burocráticos e as várias instâncias podem acabar engessando o sistema e fazendo com que novos temas não sejam incluídos nas ementas. Deve-se ressaltar que a análise feita neste trabalho estudou apenas os nomes das disciplinas e não as ementas propriamente ditas, portanto, o tema pode constar em determinadas ementas, mas não foram contemplados nesta pesquisa.

Por fim, foi realizada uma análise considerando o Conceito Preliminar de Curso (CPC), que é uma média de diferentes medidas da qualidade de um curso, sendo que as medidas utilizadas são: o Conceito Enade (que mede o desempenho dos concluintes), o desempenho dos ingressantes no Enade, o Conceito IDD e as variáveis de insumo. O dado variáveis de insumo - que considera corpo docente, infraestrutura e programa pedagógico - é formado com informações do Censo da Educação Superior e de respostas ao questionário socioeconômico do Enade (Instituto Nacional de Estudos e Pesquisas Educacionais Anísio Teixeira [Inep], 2013).

De acordo com o CPC, os 26 cursos analisados apresentaram um desempenho não muito satisfatório, sendo que 10 (38\%) dos 26 cursos da amostra possuem CPC sem conceito (SC) ou insatisfatório, conforme demonstrado na Figura 8. Para fins de avaliação, os cursos sem conceito são os cursos que não obtiveram conceito por ausência de ingressantes ou concluintes para o cálculo do CPC.

Revista de Gestão e Secretariado - GeSec, São Paulo, v. 5, n. 1, p 82-103, jan./abr. 2014. 
Figura 8 - Conceito Preliminar de Curso dos cursos que possuem disciplinas relacionadas a Educação para o desenvolvimento sustentável.

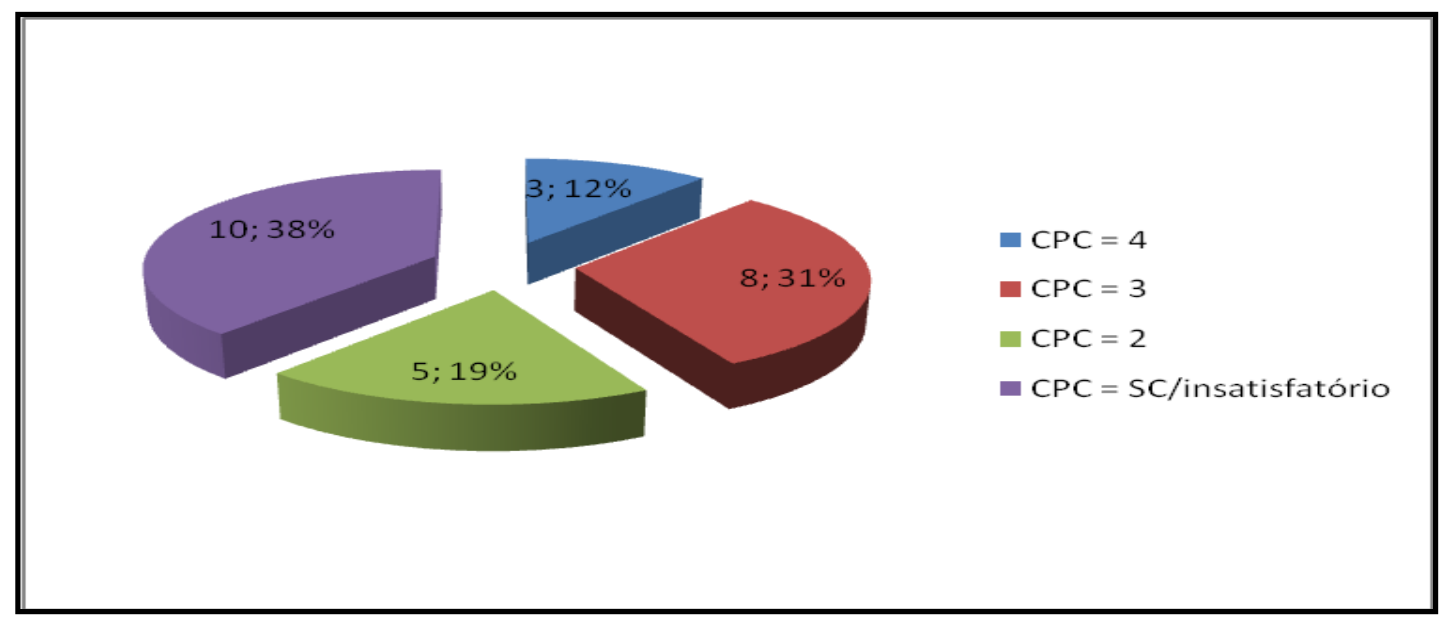

Fonte: Elaborado pelos autores.

Trinta e um por cento (oito cursos) possuem CPC igual a quatro, 19\% (cinco cursos) possuem CPC igual a 2 e apenas $12 \%$ (três cursos) possuem CPC igual a três. Nenhum curso que possui CPC 5 (conceito máximo atribuído) possui disciplinas relacionadas à Educação para o Desenvolvimento Sustentável, o que pode ser considerado uma deficiência, já que estas disciplinas são de suma importância para a formação de pessoal qualificado para atender as demandas do mercado.

\section{CONSIDERAÇÕES FINAIS}

Com esta pesquisa, concluiu-se que as disciplinas relacionadas à educação para o desenvolvimento sustentável estão presentes em apenas 26 cursos dos 86 estudados de Secretariado Executivo no grau bacharelado e na modalidade presencial. Este número mostra que os cursos estudados ainda não possuem dentre seus objetivos formar profissionais preparados para a realidade atual: o desenvolvimento sustentável. É de suma importância que disciplinas relacionadas a esta temática sejam contempladas nas estruturas curriculares como disciplinas obrigatórias, para que os egressos sejam capazes de desenvolver projetos e ações de desenvolvimento sustentável dentro de seus ambientes de trabalho.

Ao longo do estudo, foi possível perceber que os cursos ainda possuem estrutura curricular

Revista de Gestão e Secretariado - GeSec, São Paulo, v. 5, n. 1, p 82-103, jan./abr. 2014. 
engessada e com foco apenas em disciplinas técnicas e idiomas, faltando atualização em temas que importantíssimo para os futuros profissionais de Secretariado Executivo. Com isso, vale ressaltar que as coordenações de curso devem atualizar o elenco de disciplinas de acordo com a demanda do mercado.

Adequar a estrutura curricular dos cursos oferecidos não significa apenas atualizar as abordagens das áreas inseridas nas estruturas já existentes, mas sim cabe uma análise crítica do cenário no qual os futuros profissionais estarão inseridos, que além de egressos melhores preparados para o desempenho de suas atividades, também evidencia o caráter multidisciplinar que se espera de um curso de qualidade.

Foi possível perceber também que alguns cursos contemplam disciplinas apenas focadas na esfera ambiental e outros apenas na esfera social. É importante que as disciplinas foquem nestas duas áreas acrescentando ainda a esfera econômica, conforme as ideia de Almeida e Kautzmann (2012), pois é necessário reafirmar a indissociabilidade entre estas três esferas, o que também é defendido por Donaire (1999), quando apresenta o conceito de ecodesenvolvimento, que significa transformar o desenvolvimento numa soma positiva com a natureza, propondo que tenha por base o tripé: equidade social, eficiência econômica e prudência ecológica.

Pode-se inferir também que para que o estudante atinja o perfil do profissional de Secretariado Executivo constante nas diretrizes curriculares citadas (Resolução n. 3, 2005), a educação voltada para o desenvolvimento sustentável deve fazer parte da estrutura curricular, permitindo que ele tenha postura crítica e reflexiva sobre todos os aspectos da tomada de decisão do gestor que está assessorando.

Além de inserir o tema nas ementas das disciplinas, os ambientes universitários devem propiciar ao aluno vivenciar a prática do desenvolvimento sustentável, conscientizando-os dos efeitos decorrentes de suas ações diárias. A vivência cotidiana do DS pelos discentes ajudará na conscientização e na real aplicação dos conceitos ministrados pela disciplina sugerida, além de ser uma prática benéfica à instituição que a aplica.

Com isso, com base nos resultados alcançados com esta pesquisa, conclui-se que, apesar de alguns poucos cursos possuírem disciplinas que capacitam a formação de profissionais comprometidos com o desenvolvimento sustentável, este número é pequeno e precisa ser aumentado.

Com base neste estudo, percebe-se que o DS se aplica em diversas atividades que fazem parte do cotidiano do profissional de secretariado. Devido a sua posição estratégica nas instituições, ele tem a possibilidade de introduzir e difundir o tema em seu ambiente de trabalho, tanto na esfera social ou na econômica, desde que seja bem trabalhado e desenvolvido durante a graduação.

Revista de Gestão e Secretariado - GeSec, São Paulo, v. 5, n. 1, p 82-103, jan./abr. 2014. 
Ressalta-se a dificuldade encontrada devido à ausência de websites de algumas IES/Cursos de secretariado, sendo estes excluídos da amostra. Alguns cursos, apesar de possuírem uma página na internet, esta se encontra desatualizada e/ou não possui informações básicas como a estrutura curricular. É muito importante que as IES se preocupem com a divulgação do curso de Secretariado Executivo e facilitem o acesso às informações.

Após a finalização do estudo, propõe uma disciplina chamada: "Desenvolvimento sustentável aplicado ao Secretariado Executivo" com a seguinte ementa: esta disciplina propõe apresentar o conceito de Desenvolvimento Sustentável aos discentes aplicando seus conceitos no cotidiano do profissional de Secretariado Executivo. Desenvolvimento Sustentável: conceito, histórico, desafios e indicadores. Propostas e estratégias para o desenvolvimento sustentável. Educação Ambiental e Educação para o Desenvolvimento Sustentável no Brasil e no mundo. Diferentes dimensões do Desenvolvimento (ambiental, econômica, social, política, tecnológica, outras). Conflitos Socioambientais. O DS e a atuação do profissional de Secretariado Executivo.

Como procedimentos didáticos para o melhor aproveitamento do conteúdo, sugerimos o emprego de aulas teórico-conceituais com a utilização de recursos multimídia e estudos de caso e avaliação por meio de exercícios práticos, pesquisas e debates. Sugere-se também que os alunos elaborem um trabalho final prático, em que estudem organizações locais e regionais e se estas adotam políticas de DS e quais são elas. E, em caso negativo, proponham, de acordo com o conteúdo apreendido na disciplina, maneiras para que as organizações possam implementar o DS, preferencialmente através da EDS com foco no profissional de Secretariado Executivo e sua participação neste processo.

Para futuros estudos, sugere-se um estudo detalhado das ementas das disciplinas citadas na presente pesquisa, com o objetivo de verificar quais conteúdos estão sendo abordados especificamente e de que forma eles contribuem para o futuro profissional de Secretariado Executivo. Ressalta que os cursos que oferecem disciplinas relacionadas à EDS, devem atualizar suas ementas constantemente, pois este tema está em constante atualização.

Revista de Gestão e Secretariado - GeSec, São Paulo, v. 5, n. 1, p 82-103, jan./abr. 2014. 


\section{REFERÊNCIAS}

Almeida, J. C. T. \& Kautzmann, R. M. (2012). A educação ambiental (EA) na universidade e na empresa. Revista de Ciências Ambientais, 6 (1), 117-136.

Barbieri, J. C. \& Silva, D. (2011). Desenvolvimento sustentável e educação ambiental: uma trajetória comum com muitos desafios. RAM, Revista de Administração Mackenzie, 12 (3), 5182.

Demajorovic, J. \& Junior, A. V. (2006). Modelos e ferramentas de gestão ambiental: desafios e perspectivas para as organizações. São Paulo: Editora Senac.

Donaire, D. (1999). Gestão ambiental na empresa. (2a ed.) São Paulo: Atlas.

Fiates, G. G. S., Parente, E. G. V., Leite, A. L. S. \& Pfitscher, E. D. (2012). Os princípios instituídos pela organização das nações unidas para uma educação responsável em gestão: uma proposta inovadora para o ensino de administração. Revista eletrônica de estratégia e negócios, 5 (1), 3-27. Gil, A. C. (2002). Como elaborar projetos de pesquisa. (4a ed.) São Paulo: Atlas.

Hogan, D. J. (1995). Considerações sobre interdisciplinaridade. Campinas: Unicamp.

Instituto Nacional de Estudos e Pesquisas Educacionais Anísio Teixeira (2013). Indicador de qualidade das instituições de educação superior. Recuperado em 10 setembro, 2013, de http://portal.inep.gov.br/indice-geral-de-cursos

Kraemer, M. E. P. (2004). A universidade do século XXI rumo ao desenvolvimento sustentável. Revista Eletrônica de Ciência Administrativa (RECADM), 3 (2).

Kraemer, M. E. P. (2004b). Responsabilidade Social - Uma alavanca para Sustentabilidade. $\begin{array}{lllll}\text { Recuperado em } & 10 & \text { janeiro, } & \text { 2012, }\end{array}$ $\underline{\text { http://www.interfacehs.sp.senac.br/br/artigos.asp?ed=11\&cod_artigo=200 }}$

Lei 5.197, de 3 de janeiro de 1967. (1967, 5 de janeiro). Dispõe sobre a proteção à fauna e dá outras providências. Recuperado em 15 janeiro, 2013, de http://www.planalto.gov.br/ccivil_03/leis/15197.htmLei n. 9.795, de 27 de abril de 1999. (1999, 28 de abril). Dispõe sobre a educação ambiental, institui a Política Nacional de Educação Ambiental e dá outras providências. Recuperado em 20 fevereiro, 2013, de http://www.planalto.gov.br/ccivil_03/leis/19795.htmMazza, I., Oliveira, L. G. L., Ramos, R. R. \& Costa, F. J. da (2011). Importância percebida e intenções de envolvimento com a gestão social e a ambiental: uma análise comparativa junto a estudantes de curso de administração. Contextus Revista Contemporânea de Economia e Gestão, 9 (2).

Revista de Gestão e Secretariado - GeSec, São Paulo, v. 5, n. 1, p 82-103, jan./abr. 2014. 
Princípios para Educação Empresarial Responsável (PRME). Principles for responsible management education. Recuperado em 20 novembro, 2012, de http://www.unprme.org/the-6principles/index.php

Resolução n. 3 (2005, 23 de junho). Institui as Diretrizes Curriculares Nacionais para o curso de graduação em Secretariado Executivo e dá outras providências. Recuperado em 11 janeiro, 2012, de http://portal.mec.gov.br/cne/arquivos/pdf/rces003_05.pdf

Salgado, M. F. de M. A. \& Cantarino, A. A. A (2006). O papel das instituições de ensino superior na formação socioambiental dos futuros profissionais. In Encontro Nacional de Engenharia de $\begin{array}{llllll}\text { Produção. } & \text { Recuperado em } & 31 & \text { outubro, }\end{array}$ http://www.abepro.org.br/biblioteca/ENEGEP2006_TR560372_8269.pdf

Sneddon, C., Howarth, R. \& Norgaard, R. B (2006). Sustainable development in a post-Brundtland world. Ecological Economics, 57, 253-268.

Tauchen, J. \& Brandli, L. L. (2006). A gestão ambiental em instituições de ensino superior: modelo para implantação em campus universitário. Gestão \& Produção, 13 (3), 503-515.

Unesco (2000). Fórum Mundial de Educação. Cadre d'áction de Dakar. L'éducation pour tous tenir nos engagements collectifs. Recuperado em 20 outubro, 2012, de http://unesdoc.unesco.org/images/0012/001211/121147f.pdf

. (2005). Década da Educação das Nações Unidas para um Desenvolvimento Sustentável, 2005-2014: documento final do esquema internacional de implementação. Brasília: Unesco.

World Commission Environment Development (1987). Reportofthe World CommissiononEnvironmentandDevelopment: Our Common Future. Recuperado em 9 junho, 2010, de http://www.un-documents.net/wced-ocf.htm.

Revista de Gestão e Secretariado - GeSec, São Paulo, v. 5, n. 1, p 82-103, jan./abr. 2014. 